\title{
GMR
}

\section{Gene expression changes in chicken NLRC5 signal pathway associated with in vitro avian leukosis virus subgroup $\mathrm{J}$ infection}

\author{
L.L. Qiu', L. Xu' ${ }^{1}$, X.M. Guo ${ }^{1}$, Z.T. Li ${ }^{1}$, F. Wan ${ }^{1}$, X.P. Liu' ${ }^{2}$, G.H. Chen ${ }^{1}$ and \\ G.B. Chang ${ }^{1}$ \\ ${ }^{1}$ College of Animal Science and Technology, Yangzhou University, Yangzhou, \\ Jiangsu, China \\ ${ }^{2}$ Poultry Institute, Chinese Academy of Agricultural Science, Yangzhou, Jiangsu, China \\ Corresponding author: G.B. Chang \\ E-mail: passioncgb@163.com \\ Genet. Mol. Res. 15 (1): gmr. 15017640 \\ Received September 15, 2015 \\ Accepted December 29, 2015 \\ Published March 18, 2016 \\ DOI http://dx.doi.org/10.4238/gmr.15017640
}

ABSTRACT. Nucleotide-binding oligomerization domain-like receptors (NLRs) play a key role in the innate immune response as patternrecognition receptors. However, the role of NLRC5, which is a member of the NLR family, in NF-kB activation and MHC-I expression remains debatable. Infection with the $\mathrm{J}$ group avian leukosis virus (ALV-J) can result in immunosuppression and a subsequent increase in susceptibility to secondary infection. This results in huge economic losses to the poultry industry worldwide. Using quantitative real-time polymerase chain reaction (qRT-PCR), we investigated the mRNA expression levels of NLRC5 signal pathway-related genes in secondary chicken embryo fibroblasts 7 days after infection with ALV-J. The results indicated that, compared with the control groups, the expression levels of TLR7, MHC-I, and IL-18 increased significantly in the infected groups at 7 days post-infection (d.p.i.). The expression levels of NLRC5 and IL-6 were conspicuously downregulated at 7 d.p.i., but the expression levels of NF-kB, STAT1, and STAT3 were not significantly altered. These results suggest that NLRC5 and some 
genes involved in the NLRC5 pathway play a key role in antiviral immunity, typically the response to ALV-J infection. Moreover, MHC-I expression levels vary between different cell types.

Key words: Avian leukosis virus; Chicken embryo fibroblast; NLRC5; Signal pathway; Real-time PCR

\section{INTRODUCTION}

Avian leukosis, which is caused by avian leukosis viruses (ALVs), reduces growth rate and egg production in chickens (Gavora et al., 1980; Stedman and Brown, 1999). This results in significant economic losses in the broiler industry worldwide. ALVs are retroviruses that induce malignant neoplasms in poultry; those that infect chickens can be divided into seven subgroups according to their envelope antigens. ALV subgroup $\mathrm{J}$ (ALV-J) is linked to an increased incidence of tumor formation, immunosuppression, and ensuing high mortality rates (Wang et al., 2011). Despite current purification strategies, ALV-J remains a serious problem in the poultry industry because there is no effective means of dealing with it.

Nucleotide-binding oligomerization domain-like receptors (NLRs) are intracellular receptors that can respond to pathogen attacks or cellular stress. Emerging evidence suggests that the NLR family members also play a crucial role in antiviral responses (Lamkanfi and Kanneganti, 2012; Zhao and Shao, 2012). NLRC5, the largest member of the NLR protein family, has been identified as a critical regulator of innate and adaptive immune responses (Yao and Qian, 2013). As with other NLRs, NLRC5 contains three structural domains: the N-terminal atypical caspase activation and recruitment domain; the centrally located NACHT domain; and 27 leucine-rich repeats at the C-terminal (Lian et al., 2012). Recently, NLRC5 has been shown to play a role not only in the regulation of the inflammasome signaling pathway, but also in the NF-кB pathway, and antiviral innate immune responses (Cui et al., 2010; Kuenzel et al., 2010; Neerincx et al., 2010; Allen et al., 2011). Although NLRC5 plays a key role in antiviral responses, its role in innate immunity remains controversial and unresolved; recent research has offered discrepant functions for NLRC5 in innate and adaptive immunity (Cui et al., 2010; Kumar et al., 2011), which require further studies to resolve.

In the current study, we compared the expression of genes that related to the NLRC5 signal pathway in ALV-J-infected and control groups, and investigated gene expression changes in the NLRC5 signal pathway, with the aim of providing a new basis for the better understanding of NLRC5 function in the chicken immune response.

\section{MATERIAL AND METHODS}

\section{Infection of chicken embryo fibroblasts (CEFs) with ALV-J virus}

Primary cultures of CEFs derived from 10-day-old specific-pathogen-free chicken embryos (Jinan Sais Poultry Co., Ltd., Shandong Province, China) were deposited in $25-\mathrm{cm}^{2}$ cell-culture flasks. After several days, the cells were passaged and seeded at a concentration of approximately $10^{6}$ cells/well on 6-well culture plates. Throughout derivation and culture, the cells were grown in Dulbecco's modified Eagle's medium (Hyclone, USA) supplemented with $10 \%$ fetal bovine serum (FBS) (Gibco, USA) in a humidified incubator at $37^{\circ} \mathrm{C}$ and $5 \% \mathrm{CO}_{2}$. The cells were then infected with $100 \mathrm{TCID}_{50}(50 \%$ tissue culture infective dose) ALV-J strain, obtained from Shandong 
Agricultural University, China. After $3 \mathrm{~h}$ of incubation, the virus was removed and the cells were further incubated in media with 1\% FBS. Host-virus interactions were tested in duplicate wells, which were harvested 0,24 , and $168 \mathrm{~h}$ post-infection for RNA extraction.

\section{RNA extraction and complementary DNA (cDNA) synthesis}

Total RNA was extracted from each sample using the TRIzol method and the concentration and quality of RNA were detected using a NanoDrop 1000 spectrophotometer (Thermo Fisher). cDNA was synthesized using a FastQuant RT Kit (with gDNase) (Tiangen, China) according to the manufacturer instructions, and stored at $-20^{\circ} \mathrm{C}$ until required for real-time $\mathrm{PCR}$ testing.

\section{Real-time PCR}

According to the sequences of the NLRC5 pathway-related and housekeeping genes published on the GenBank database, primers were designed using the Oligo7.0 software and synthesized by the Shanghai Sangon Biotechnology Company (Table 1).

Table 1. Primers used for real-time polymerase chain reaction (PCR).

\begin{tabular}{|c|c|c|c|c|}
\hline Gene symbol & Primer sequences $\left(5^{\prime}-3^{\prime}\right)$ & Accession No. & Amplification (bp) & Annealing temperature $\left({ }^{\circ} \mathrm{C}\right)$ \\
\hline GP37 & $\begin{array}{l}\text { F: TGCGTGCGTGGTTATTATTTC } \\
\text { R: AATGGTGAGGTCGCTGACTGT }\end{array}$ & NC_015116.1 & 198 & 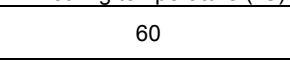 \\
\hline TLR7 & $\begin{array}{l}\text { F: CCTGACCCTGACTATTAACCAT } \\
\text { R: CGTAAAGTAGCAGGAAGACCC }\end{array}$ & NM_001011691 & 246 & 60 \\
\hline$N F-\kappa B$ & $\begin{array}{l}\text { F: TGAACGGATCCGCACCAATA } \\
\text { R: CGTTCACCCACACCTGGAAG }\end{array}$ & NM_205129.1 & 107 & 60 \\
\hline MHC-I & $\begin{array}{l}\text { F: ACAAGTACCAGTGCCGCGTG } \\
\text { R: CGCGATGTTGTAGCCCTTCC }\end{array}$ & NM_001097530.1 & 197 & 60 \\
\hline IL-6 & $\begin{array}{l}\text { F: GCTACAGCACAAAGCACCTG } \\
\text { R: GACTTCAGATTGGCGAGGAG }\end{array}$ & AJ250838 & 112 & 60 \\
\hline$I L-18$ & $\begin{array}{l}\text { F: AGGTGAAATCTGGCAGTGGAAT } \\
\text { R: ACCTGGACGCTGAATGCAA }\end{array}$ & AJ276026 & 94 & 63.5 \\
\hline STAT1 & $\begin{array}{l}\text { F: CCGATACACATGGCAATGATAA } \\
\text { R: TGCATCAAGCTCCTTCTGTTTA }\end{array}$ & NM_001012914 & 147 & 60 \\
\hline STAT3 & $\begin{array}{l}\text { F: TAGTGCTGCTCCGTATCTGAAG } \\
\text { R: CAGGTCAATGGTATTGCTGAAG }\end{array}$ & NM_001030931.1 & 73 & 60 \\
\hline NLRC5 & $\begin{array}{l}\text { F: TGAGCTACACGTCAGGAAGGA } \\
\text { R: GCTCTGCAGAATGGACACAA }\end{array}$ & JQ044414.1 & 193 & 60 \\
\hline GAPDH & $\begin{array}{l}\text { F: CGATCTGAACTACATGGTTTAC } \\
\text { R: TCTGCCCATTTGATGTTGC }\end{array}$ & NM_204305 & 151 & 60 \\
\hline
\end{tabular}

Real-time PCRs were performed on an ABI 7500 Real-time PCR Detection System (Applied Biosystems, USA) with Ultra SYBR Mixture reagent (with ROX) (CoWin Biotechnology Company, China). The $20-\mu \mathrm{L}$ reaction volume comprised $10 \mu \mathrm{L} 2 \mathrm{X}$ Ultra SYBR Mixture (with ROX), $0.5 \mu \mathrm{M}$ each primer, and $2 \mu \mathrm{L}$ cDNA. The following PCR cycling profile was used: one single step at $95^{\circ} \mathrm{C}$ for $10 \mathrm{~min}$, followed by 40 cycles of $95^{\circ} \mathrm{C}$ for $15 \mathrm{~s}$ and $60^{\circ} \mathrm{C}$ for $1 \mathrm{~min}$, ending with a melting curve analysis of $95^{\circ} \mathrm{C}$ for $15 \mathrm{~s}, 60^{\circ} \mathrm{C}$ for $1 \mathrm{~min}, 95^{\circ} \mathrm{C}$ for $15 \mathrm{~s}$, and $60^{\circ} \mathrm{C}$ for $15 \mathrm{~s}$.

\section{Statistical analysis of data}

Statistical significance was determined by the $t$-test using the SPSS v13.0 software, and a value of 0.05 was considered significant when compared with the respective controls. The results are represented as $2^{-\Delta \Delta C t}$. 


\section{RESULTS}

\section{mRNA expression levels of ALV-J transmembrane protein GP37}

The transmembrane protein encoded by the GP37 gene plays a critical role when virus fusion with the cell membrane occurs. In this study, the GP37 gene was used for the detection of ALV-J load at 1 and 7 days post-infection by relative PCR quantitative testing. ALV-J load was measured as the ALV-J relative copy number.

The results revealed that at 7 days after ALV-J infection, the relative expression levels of the ALV-J GP37 gene, which encodes a transmembrane protein, were considerably elevated (Figure 1). Therefore, we investigated the NLRC5-mediated antiviral pathway and inflammatory cytokines in CEF cells infected with avian leukosis virus at 7 days.

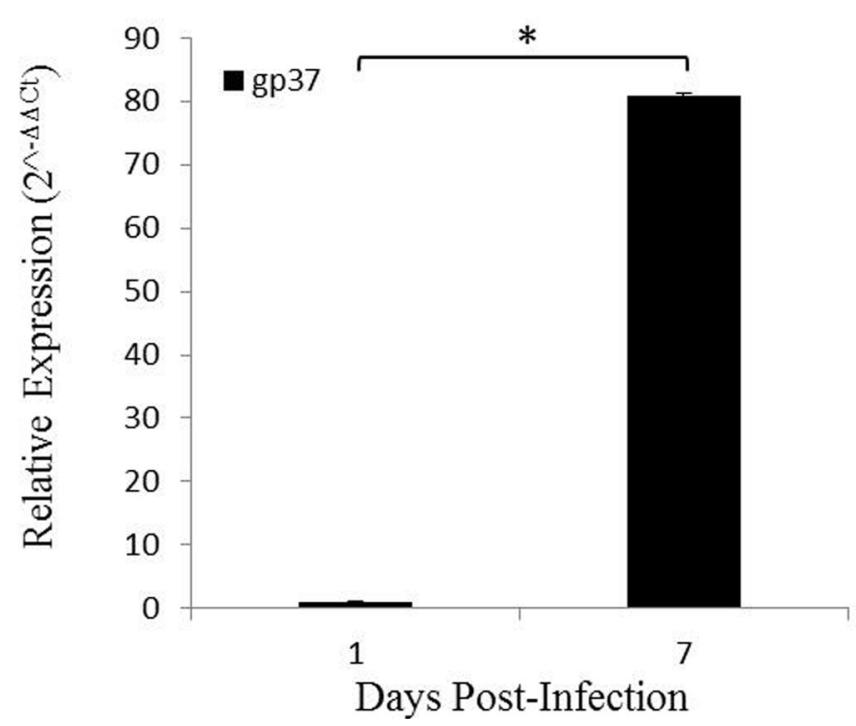

Figure 1. Levels of $\mathrm{J}$ group avian leukosis virus (ALV-J) GP37 mRNA transcription at 1 and 7 days after ALV-J infection $\left({ }^{*} \mathrm{P}<0.05\right)$.

\section{Gene expression changes in the NLRC5 signal pathway at 7 days post-ALV-J infection}

As can be seen from Figure 2, the expression levels of TLR7, MHC-I, and IL-18 were significantly upregulated in ALV-J-infected secondary CEF cells compared with the negative controls at 7 days post infection (d.p.i.) ( $<$ 0.05). The expression levels of NLRC5 and IL-6 showed sharp downregulation $(P<0.05)$, and STAT1 expression decreased in infected groups compared with control groups at 7 d.p.i. However, there were no significant differences in the expression levels of NF-кB and STAT3 between the virus-treated and control groups at 7 d.p.i. in the secondary CEF cells. 

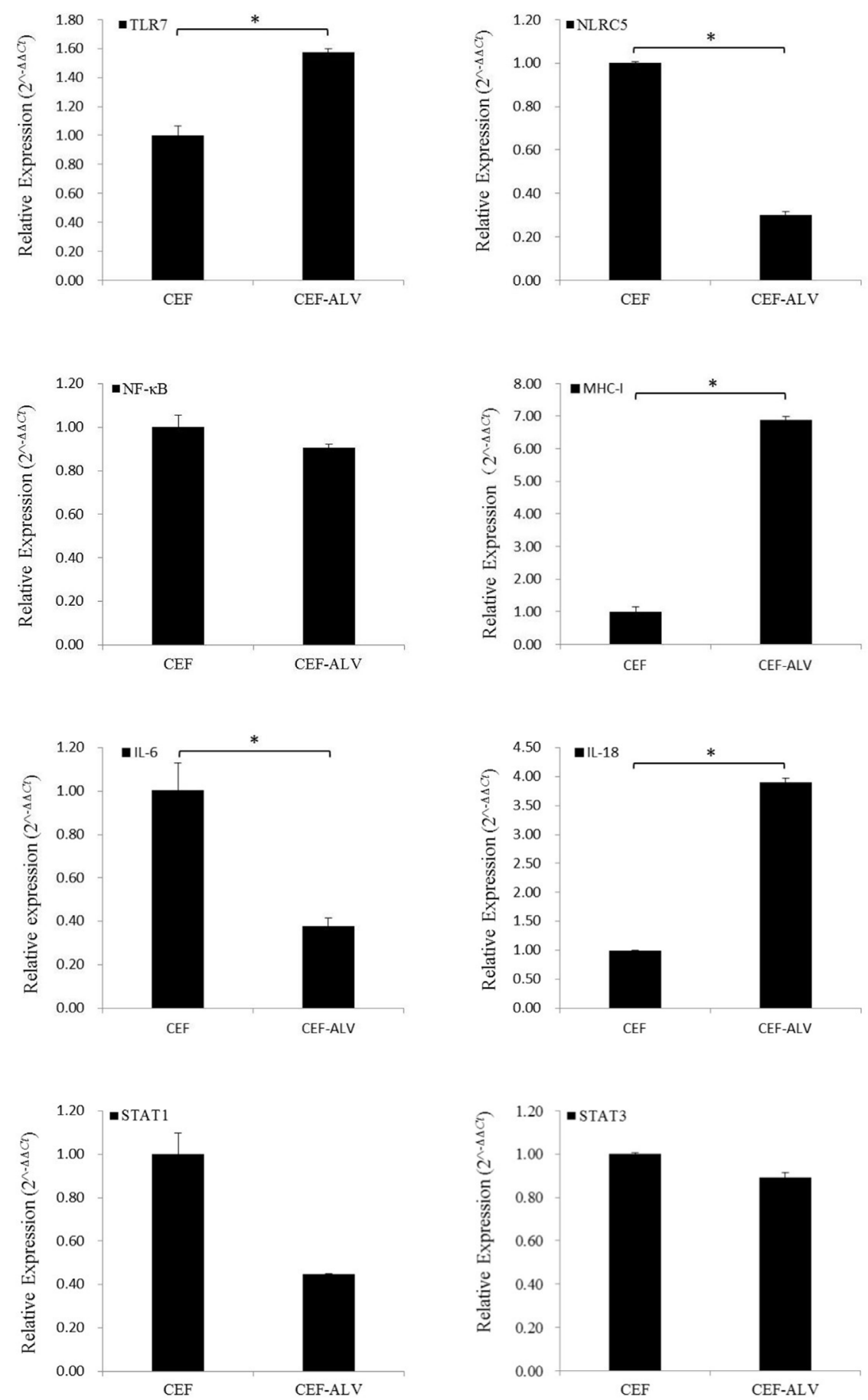

Figure 2. Gene mRNA expression changes (i.e., control group levels/infected group levels) in chicken embryo fibroblast (CEF) cells at 7 days after $\mathrm{J}$ group avian leukosis virus (ALV-J) infection $\left({ }^{*} P<0.05\right)$. 


\section{DISCUSSION}

Viral RNA is recognized by Toll-like receptors and RIG-l-like receptors; TLR7 recognizes single-strand RNA and induces the innate immune response (Oshiumi et al., 2011). TLR7 transduces the virus infection signal and triggers downstream signaling events, such as the activation of NF- $\mathrm{B}$ and inflammatory cytokines (Zeng et al., 2014). In this study, two cytokines, IL-6 and IL-18, were chosen for detection and analysis because they are the most important signaling molecules in the immune response. IL-6 is a multifunctional cytokine and is closely involved in oncogenesis owing to its influence on the differentiation of CD4+ cells (McGovern et al., 2012; Tippenhauer et al., 2013; Moon et al., 2014). IL-18 is a proinflammatory cytokine, and can be expressed extensively in a wide variety of cells.

In the present study, the significant increases in the expression levels of TLR7, MHC-I, and IL-18 at 7 d.p.i. in CEF cells might be attributable to the rapid replication of ALV-J, which induces antiviral immunity, as shown in Figure 1. In this study, we observed an IL-18 expression pattern that was similar to that reported by Gao et al. (2015) in ALV-J infections in vivo. The discrepancies between the two observations might be attributable to the different objects infected by the virus at different time-points. Research has shown that NLRC5 might negatively regulate NF- $\mathrm{BB}-$ dependent responses (Cui et al., 2010). However, in this study, at 7 d.p.i. the expression of NLRC5 was conspicuously downregulated, although there was no significant change in the level of NF- $\kappa B$ expression. This might depend on the detection time-point, which we may have missed.

MHC-I plays a vital role in the immune defense against viruses and tumors. Two recent reports revealed a potential involvement of NLRC5 in MHC class I gene expression, but arrived at opposing conclusions (Benko et al., 2010; Meissner et al., 2010). Benko et al. (2010) showed that NLRC5 is a negative modulator in RAW264.7, whereas Meissner et al. (2010) found that NLRC5 might enhance MHC-I expression by activating the promoters in HeLa, HEK293T, and Jurkat cells. In this study, the expression levels of MHC-I at 7 d.p.i. increased sharply while NLRC5 expression levels conspicuously decreased; we agree with Benko et al. (2010). In NLRC5-deficient B cells from the spleen and CD11C+ dendritic cells, the expression of MHC-I decreased (Biswas et al., 2012). Obviously, MHC-I is involved in antiviral immunity, and we can conclude from this study that the type of host cell influences the outcome.

\section{Conflicts of interest}

The authors declare no conflict of interest.

\section{ACKNOWLEDGMENTS}

Research supported by the National Natural Science Foundation of China (\#31172199 and \#31301966) and the Science \& Technology Pillar Program of Jiangsu (\#BE2013392).

\section{REFERENCES}

Allen IC, Moore CB, Schneider M, Lei Y, et al. (2011). NLRX1 protein attenuates inflammatory responses to infection by interfering with the RIG-I-MAVS and TRAF6-NF-kB signaling pathways. Immunity 34: 854-865. http://dx.doi.org/10.1016/j. immuni.2011.03.026

Benko S, Magalhaes JG, Philpott DJ and Girardin SE (2010). NLRC5 limits the activation of inflammatory pathways. J. Immunol. 185: 1681-1691. http://dx.doi.org/10.4049/jimmunol.0903900

Biswas A, Meissner TB, Kawai T and Kobayashi KS (2012). Cutting edge: impaired MHC class I expression in mice deficient for NIrc5/class I transactivator. J. Immunol. 189: 516-520. http://dx.doi.org/10.4049/jimmunol.1200064 
Cui J, Zhu L, Xia X, Wang HY, et al. (2010). NLRC5 negatively regulates the NF-kappaB and type I interferon signaling pathways. Cell 141: 483-496. http://dx.doi.org/10.1016/j.cell.2010.03.040

Gao Y, Liu Y, Guan X, Li X, et al. (2015). Differential expression of immune-related cytokine genes in response to J group avian leukosis virus infection in vivo. Mol. Immunol. 64: 106-111. http://dx.doi.org/10.1016/j.molimm.2014.11.004

Gavora JS, Spencer JL, Gowe RS and Harris DL (1980). Lymphoid leukosis virus infection: effects on production and mortality and consequences in selection for high egg production. Poult. Sci. 59: 2165-2178. http://dx.doi.org/10.3382/ps.0592165

Kuenzel S, Till A, Winkler M, Häsler R, et al. (2010). The nucleotide-binding oligomerization domain-like receptor NLRC5 is involved in IFN-dependent antiviral immune responses. J. Immunol. 184: 1990-2000. http://dx.doi.org/10.4049/ jimmunol.0900557

Kumar H, Pandey S, Zou J, Kumagai Y, et al. (2011). NLRC5 deficiency does not influence cytokine induction by virus and bacteria infections. J. Immunol. 186: 994-1000. http://dx.doi.org/10.4049/jimmunol.1002094

Lamkanfi M and Kanneganti TD (2012). Regulation of immune pathways by the NOD-like receptor NLRC5. Immunobiology 217: 13-16. http://dx.doi.org/10.1016/j.imbio.2011.08.011

Lian L, Ciraci C, Chang G, Hu J, et al. (2012). NLRC5 knockdown in chicken macrophages alters response to LPS and poly (I:C) stimulation. BMC Vet. Res. 8: 23. http://dx.doi.org/10.1186/1746-6148-8-23

McGovern JL, Nguyen DX, Notley CA, Mauri C, et al. (2012). Th17 cells are restrained by Treg cells via the inhibition of interleukin-6 in patients with rheumatoid arthritis responding to anti-tumor necrosis factor antibody therapy. Arthritis Rheum. 64: 3129-3138. http://dx.doi.org/10.1002/art.34565

Meissner TB, Li A, Biswas A, Lee KH, et al. (2010). NLR family member NLRC5 is a transcriptional regulator of MHC class I genes. Proc. Natl. Acad. Sci. USA 107: 13794-13799. http://dx.doi.org/10.1073/pnas.1008684107

Moon YM, Lee J, Lee SY, Her YM, et al. (2014). Gene associated with retinoid-interferon-induced mortality 19 attenuates murine autoimmune arthritis by regulation of th17 and treg cells. Arthritis Rheumatol. 66: 569-578. http://dx.doi.org/10.1002/ art.38267

Neerincx A, Lautz K, Menning M, Kremmer E, et al. (2010). A role for the human nucleotide-binding domain, leucine-rich repeatcontaining family member NLRC5 in antiviral responses. J. Biol. Chem. 285: 26223-26232. http://dx.doi.org/10.1074/jbc. $\underline{\mathrm{M} 110.109736}$

Oshiumi H, Matsumoto M and Seya T (2011). [Innate immune response to RNA virus infection]. Uirusu 61: 153-161. http:// dx.doi.org/10.2222/jsv.61.153

Stedman NL and Brown TP (1999). Body weight suppression in broilers naturally infected with avian leukosis virus subgroup J. Avian Dis. 43: 604-610. http://dx.doi.org/10.2307/1592664

Tippenhauer M, Heller DE, Weigend S and Rautenschlein S (2013). The host genotype influences infectious bursal disease virus pathogenesis in chickens by modulation of T cells responses and cytokine gene expression. Dev. Comp. Immunol. 40: 1-10. http://dx.doi.org/10.1016/j.dci.2012.10.013

Wang F, Wang X, Chen H, Liu J, et al. (2011). The critical time of avian leukosis virus subgroup J-mediated immunosuppression during early stage infection in specific pathogen-free chickens. J. Vet. Sci. 12: 235-241. http://dx.doi.org/10.4142/ jvs.2011.12.3.235

Yao Y and Qian Y (2013). Expression regulation and function of NLRC5. Protein Cell 4: 168-175. http://dx.doi.org/10.1007/ s13238-012-2109-3

Zeng S, Feng Z and Liu Y and Yang Z (2014). The induction of TLRs-mediated antiviral signaling pathway and inflammatory cytokine in chicken embryo fibroblasts infected with Newcastle disease virus. J. Sichuan Agric. Univ 32: $436-441$.

Zhao Y and Shao F (2012). NLRC5: a NOD-like receptor protein with many faces in immune regulation. Cell Res. 22: 10991101. http://dx.doi.org/10.1038/cr.2012.83 